\title{
TU/e EmonONEN

\section{Electric field and temperature in a target induced by a plasma jet imaged using Mueller polarimetry}

\section{Citation for published version (APA):}

Slikboer, E. T., Sobota, A., Guaitella, O., \& Garcia-Caurel, E. (2018). Electric field and temperature in a target induced by a plasma jet imaged using Mueller polarimetry. Journal of Physics D: Applied Physics, 51(2),

[025204 ]. https://doi.org/10.1088/1361-6463/aa9b17

DOI:

10.1088/1361-6463/aa9b17

Document status and date:

Published: $17 / 01 / 2018$

\section{Document Version:}

Publisher's PDF, also known as Version of Record (includes final page, issue and volume numbers)

\section{Please check the document version of this publication:}

- A submitted manuscript is the version of the article upon submission and before peer-review. There can be important differences between the submitted version and the official published version of record. People interested in the research are advised to contact the author for the final version of the publication, or visit the $\mathrm{DOI}$ to the publisher's website.

- The final author version and the galley proof are versions of the publication after peer review.

- The final published version features the final layout of the paper including the volume, issue and page numbers.

Link to publication

\section{General rights}

Copyright and moral rights for the publications made accessible in the public portal are retained by the authors and/or other copyright owners and it is a condition of accessing publications that users recognise and abide by the legal requirements associated with these rights.

- Users may download and print one copy of any publication from the public portal for the purpose of private study or research.

- You may not further distribute the material or use it for any profit-making activity or commercial gain

- You may freely distribute the URL identifying the publication in the public portal.

If the publication is distributed under the terms of Article 25fa of the Dutch Copyright Act, indicated by the "Taverne" license above, please follow below link for the End User Agreement:

www.tue.nl/taverne

Take down policy

If you believe that this document breaches copyright please contact us at:

openaccess@tue.nl

providing details and we will investigate your claim. 
PAPER

\section{Electric field and temperature in a target induced by a plasma jet imaged using Mueller polarimetry}

To cite this article: Elmar Slikboer et al 2018 J. Phys. D: Appl. Phys. 51025204

View the article online for updates and enhancements.
Related content

Charge transfer to a dielectric target by guided ionization waves using electric field measurements

Elmar Slikboer, Enric Garcia-Caurel, Olivier Guaitella et al.

Time-resolved electric field measurements during and after the initialization of a $\mathrm{kHz}$ plasma jet-from streamers to quided streamers

Elmar Slikboer, Olivier Guaitella and Ana Sobota

Phase-resolved measurement of electric charge deposited by an atmospheric pressure plasma jet on a dielectric surface R Wild, T Gerling, R Bussiahn et al. 


\title{
Electric field and temperature in a target induced by a plasma jet imaged using Mueller polarimetry
}

\author{
Elmar Slikboer ${ }^{1,2,3,4} \oplus$, Ana Sobota ${ }^{2} \oplus$, Olivier Guaitella ${ }^{3}$ \\ and Enric Garcia-Caurel ${ }^{1}$ (B)
}

1 LPICM, CNRS, Ecole Polytechnique, Université Paris-Saclay, 91128 Palaiseau, France
2 Department of Applied Physics, EPG, Eindhoven University of Technology, Netherlands
${ }^{3}$ LPP, CNRS, Ecole Polytechnique, UPMC, Université Paris-Saclay, 91128 Palaiseau, France

E-mail: elmar-theodorus.slikboer@polytechnique.edu

Received 20 September 2017, revised 5 November 2017

Accepted for publication 16 November 2017

Published 15 December 2017

\begin{abstract}
Mueller polarimetry is used to investigate the behavior of an electro optic target (BSO crystal) under exposure of guided ionization waves produced by an atmospheric pressure plasma jet. For the first time, this optical technique is time resolved to obtain the complete Mueller matrix of the sample right before and after the impact of the discharges. By analyzing the induced birefringence, the spatial profiles and local values are obtained of both the electric field and temperature in the sample. Electric fields are generated due to deposited surface charges and a temperature profile is present, due to the heat transferred by the plasma jet. The study of electric field dynamics and local temperature increase at the target, due to the plasma jet is important for biomedical applications, as well as surface functionalization. This work shows how Mueller polarimetry can be used as a novel diagnostic to simultaneously acquire the spatial distribution and local values of both the electric field and temperature, by coupling the external source of anisotropy to the measured induced birefringence via the symmetry point group of the examined material.
\end{abstract}

Keywords: non-thermal atmospheric pressure plasma, plasma jet, electric field, ionization waves, Mueller polarimetry, dielectric target, electro-optic crystals

(Some figures may appear in colour only in the online journal)

\section{Introduction}

Atmospheric pressure plasma jets have been used in recent decades for numerous applications. Because plasma jets are non-thermal, two of the most rapidly growing fields are surface functionalization [1] and plasma medicine [2] to treat e.g. various biomedical surfaces [3-5]. In order to understand what is happening in the treated sample and how the discharges are produced by the plasma jet, it is important to have various diagnostic tools available.

This work presents an imaging diagnostic based on Mueller polarimetry, which was designed to investigate electric fields

${ }^{4}$ Author to whom any correspondence should be addressed. and charge deposition at a dielectric target, due to the impact of guided ionization waves generated by the plasma jet. It is found that using Mueller polarimetry to investigate an electrooptic BSO crystal, it also allows us to obtain the temperature profile induced in the target. BSO crystals have been used in the past for the investigation of electric fields generated in targets by a plasma jet [6] and surface charge deposition by DBDs [7].

Mueller polarimetry is an optical technique to investigate a material by capturing the complete Mueller matrix, measuring the change of the polarization of light that interacts with the material $[8,9]$. The Mueller matrix is a general tool to describe the optical properties of a material [10]. 

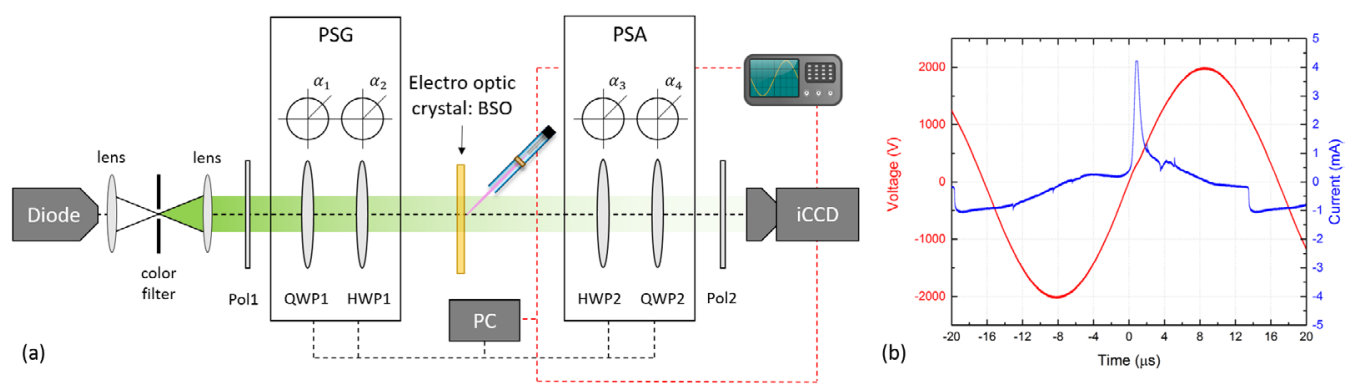

Figure 1. Experimental polarimetry setup (a) used to obtain time resolved imaging Mueller matrices of electro optic crystals under exposure of an atmospheric pressure plasma jet. External triggering provided by current measurements (b) on the plasma jet is coupled with the control of the liquid crystals within the polarizer stage generator and analyzer (PSG and PSA) and the acquisition of the ICCD camera. The optical axis of the system is referred to as the $z$-axis

\section{The basics of Mueller polarimetry}

The polarimeter, shown in figure 1, consists of two polarizers and four ferroelectric liquid crystals. These liquid crystals relate to two half-wave plates and two quarter-wave plates, with controllable orientations. Their orientation depends on the voltage applied and their initial orientations $\alpha_{i}$ [11]. As such, the amount of light coming from the diode reaching the ICCD camera is controlled.

By subsequentially applying a positive or negative voltage to the four liquid crystals, 16 different intensity images are retrieved, forming a 4 by 4 matrix $B$. Matrix $B$ is transformed to the Mueller matrix of the sample using the Mueller matrices of the PSA and PSG. These two matrices are obtained through a calibration, using four calibration samples [12]. During calibration, the plasma jet and electro optic target are removed. The first calibration sample is a measurement performed of air, while the other three consist of two polarizers (horizontally and vertically) and a retarder at $30^{\circ}$. This provides four intensity matrices that are used to characterize the PSA and PSG following the calibration eigenvalue method [12].

The obtained Mueller matrix of a sample contains all the optical properties but the information is entangled, as such it has to be analyzed properly [9]. For measurements done in transmission of continous materials, the basic polarimetric properties are retrieved using the logarithmic decomposition [13-15]. This approach implicates that the total optical properties result from the accumulation along the optical path $(z$-axis) through the material.

By taking the logarithm of the Mueller matrix $M$, the differential matrix is obtained and separated into depolarization and non-depolarization parts [14]. The non-depolarization matrix $L_{m}$ contains diattenuation and birefringence. See equation (1) with $L$ indicating linear polarized light (in 0/90 coordinate system) and $C$ circular polarized light. An apostrophe $'$ is added to indicate linearly polarized light in the diagonal system $(45 / 135 \mathrm{deg})$. The optical properties diattenuation and birefringence are indicated with $D$ and $B$, respectively. As such, elements $\{2,4\}$ and $\{4,2\}$ show the linear birefringence in the diagonal system. Throughout this article, specific elements within the logarithmic decomposed matrix are denoted using curly brackets \{\} .

$$
L_{m}=\left(\begin{array}{cccc}
0 & L D & L D^{\prime} & C D \\
L D & 0 & C B & L B^{\prime} \\
L D^{\prime} & -C B & 0 & L B \\
C D & -L B^{\prime} & -L B & 0
\end{array}\right)
$$

\section{Externally induced birefringence}

Birefringence in a material occurs when the orthogonal components of an electromagnetic wave travels through the material with different velocities, due to a difference in the refractive index [16]. A material's refractive index can be described using the index ellipsoid, see equation (2) with $x$, $y$ and $z$ the optical axis of the material and $n_{i}$ the respective refractive index [17]. Normally, BSO is an isotropic crystal with refractive index $n_{o}=2.54$, but anisotropy can be induced externally via electric field or stress. Then, the index ellipsoid changes, generally described by adding six terms $\Delta \eta_{i}$ to the impermeability tensor $A$ [18], see equation (3). These terms depend on the external source of anisotropy.

$$
\begin{gathered}
\frac{x^{2}}{n_{x}^{2}}+\frac{y^{2}}{n_{y}^{2}}+\frac{z^{2}}{n_{z}^{2}}=0 \\
\Rightarrow\left(\begin{array}{lll}
x & y & z
\end{array}\right) \cdot A \cdot\left(\begin{array}{l}
x \\
y \\
z
\end{array}\right)=1 \\
\text { with } A=\left(\begin{array}{ccc}
\frac{1}{n_{x}^{2}}+\Delta \eta_{1} & \Delta \eta_{6} & \Delta \eta_{5} \\
\Delta \eta_{6} & \frac{1}{n_{y}^{2}}+\Delta \eta_{2} & \Delta \eta_{4} \\
\Delta \eta_{5} & \Delta \eta_{4} & \frac{1}{n_{z}^{2}}+\Delta \eta_{3}
\end{array}\right) .
\end{gathered}
$$

To calculate the induced birefringence, the resulting two dimensional ellipse formed after intersecting the ellipsoid and the plane wave, see equation (4) with $\vec{k}=\left(k_{x}, k_{y}, k_{z}\right)$, has to be investigated [19].

$$
k_{x} \cdot x+k_{y} \cdot y+k_{z} \cdot z=0 .
$$

In this research, the BSO crystal is used in transmission where light travels through it at normal incidence. This means the direction of propagation is parallel to the $z$-axis, 
i.e. $k_{x}=k_{y}=z=0$, and the index ellipsoid simplifies into an ellipse in the $X Y$-plane, described by equation (5).

$$
x^{2}\left(\frac{1}{n_{o}^{2}}+\Delta \eta_{1}\right)+y^{2}\left(\frac{1}{n_{o}^{2}}+\Delta \eta_{2}\right)+2 x y \Delta \eta_{6}=1 .
$$

The axis of this ellipse is investigated, which corresponds to the experienced refractive index. The axis that has to be taken into account is determined by the polarization direction of the light.

Two independent cases are measured using Mueller polarimetry, respectively, when light is polarized along the $x$ and $y$-axes (the $0 / 90^{\circ}$ coordinate system) or along the diagonals (the $45 / 135^{\circ}$ coordinate system). Birefringence in the first coordinate system is referred to as $L B$ and in the second as $L B^{\prime}$, defined by equation (6), with $d=0.5 \mathrm{~mm}$ the travelling distance through the material (thickness of the crystal), $\lambda=530 \mathrm{~nm}$ the wavelength of light and $\Delta n$ the experienced difference of refractive indices in a certain coordinate system.

$$
L B=\frac{2 \pi \mathrm{d}}{\lambda} \Delta n_{0 / 90^{\circ}} \text { and } L B^{\prime}=\frac{2 \pi \mathrm{d}}{\lambda} \Delta n_{45 / 135^{\circ}} .
$$

To evaluate $L B$, the experienced refractive indices along the $x$ and $y$-axes are calculated using equation (5). The induced anisotropy terms $\Delta \eta$ are assumed to be small enough to allow a Taylor expansion, see equations (7) and (8).

$$
\begin{aligned}
y \rightarrow 0 & \Rightarrow x^{2}\left(\frac{1}{n_{o}^{2}}+\Delta \eta_{1}\right)=1 \\
& \Leftrightarrow x \cong \pm n_{o}\left(1-\frac{1}{2} \Delta \eta_{1} n_{o}^{2}\right) \\
x \rightarrow 0 & \Rightarrow y^{2}\left(\frac{1}{n_{o}^{2}}+\Delta \eta_{2}\right)=1 \\
& \Leftrightarrow y \cong \pm n_{o}\left(1-\frac{1}{2} \Delta \eta_{2} n_{o}^{2}\right) .
\end{aligned}
$$

The difference is taken from the experienced refractive indices to obtain $\Delta n_{0 / 90^{\circ}}$, see equation (9). For the birefringence $L B^{\prime}$, the refractive indices along the diagonals are examined, assuming $x=y$ and $x=-y$. Again, a Taylor expansion is used and the difference is taken to evaluate $\Delta n_{45 / 135^{\circ}}$; see the results given by equation (10).

$$
\begin{aligned}
\Delta n_{0 / 90^{\circ}} & =\frac{1}{2} n_{o}^{3}\left(\Delta \eta_{1}-\Delta \eta_{2}\right) \\
\Delta n_{45 / 135^{\circ}} & =n_{o}^{3} \Delta \eta_{6} .
\end{aligned}
$$

External electric field can induce anisotropy in materials according to the Pockels effect and Kerr effect. The linear relation between the refractive index and electric field is described by the Pockels effect, which only occurs in materials that lack an inversion symmetry [20]. This includes the BSO crystal used in this research. Since the Pockels effect is of first order, the Kerr effect can be neglected in BSO. The $\Delta \eta_{i}$ terms from the perturbed index ellipsoid are coupled with the external electric field $\vec{E}=\left(E_{x}, E_{y}, E_{z}\right)$ by using the electro optic tensor [18]:

$$
\left(\begin{array}{c}
\Delta \eta_{1} \\
\Delta \eta_{2} \\
\Delta \eta_{3} \\
\Delta \eta_{4} \\
\Delta \eta_{5} \\
\Delta \eta_{6}
\end{array}\right)=\overline{\boldsymbol{T}} \cdot \vec{E}=\left(\begin{array}{ccc}
0 & 0 & 0 \\
0 & 0 & 0 \\
0 & 0 & 0 \\
r_{41} & 0 & 0 \\
0 & r_{41} & 0 \\
0 & 0 & r_{41}
\end{array}\right) \cdot\left(\begin{array}{c}
E_{x} \\
E_{y} \\
E_{z}
\end{array}\right)
$$

The specific electro-optic tensor $\bar{T}$ of BSO is found in the literature [18], which is substituted to get the final relation for $L B$ and $L B^{\prime}$ as a function of the electric field components. For BSO, the only electro-optic constant present is $r_{41}$, which is determined by the manufacturer of the BSO crystal and given by $4.8 \cdot 10^{-12} \mathrm{~V} \mathrm{~m}^{-1}$ [21]. We verified this value experimentally. The unperturbed refractive index $n_{o}$ is 2.54 . Equation (12) shows that no retardance is expected in the 0/90 coordinate system and that the retardance experienced in the diagonal system only depends on $E_{z}$, regardless of any radial electric field.

$$
\left\{\begin{array}{l}
L B=\frac{2 \pi \mathrm{d}}{\lambda} \Delta n_{0 / 90^{\circ}}=0 \\
L B^{\prime}=\frac{2 \pi \mathrm{d}}{\lambda} \Delta n_{45 / 135^{\circ}}=\frac{2 \pi \mathrm{d}}{\lambda} n_{o}^{3} r_{41} E_{z}
\end{array}\right.
$$

Additional to the electric field, strain or stress in a material can also cause birefringence. In this case, the $\Delta \eta_{i}$ terms are coupled with the strain vector $\vec{S}=\left(S_{1}, S_{2}, S_{3}, S_{4}, S_{5}, S_{6}\right)$ using the photo-elastic tensor. The specific photo-elastic tensor $\overline{\boldsymbol{P}}$ of BSO is again found in the literature [18], while unfortunately only limited values of the tensor elements are reported in [22] given by $p_{11}=0.16, p_{12}=0.13$ and $p_{44}=0.12$.

$$
\begin{aligned}
& \left(\begin{array}{c}
\Delta \eta_{1} \\
\Delta \eta_{2} \\
\Delta \eta_{3} \\
\Delta \eta_{4} \\
\Delta \eta_{5} \\
\Delta \eta_{6}
\end{array}\right)=\overline{\boldsymbol{P}} \cdot \vec{S} \\
& =\left(\begin{array}{cccccc}
p_{11} & p_{12} & p_{21} & 0 & 0 & 0 \\
p_{21} & p_{11} & p_{12} & 0 & 0 & 0 \\
p_{12} & p_{21} & p_{11} & 0 & 0 & 0 \\
0 & 0 & 0 & p_{44} & 0 & 0 \\
0 & 0 & 0 & 0 & p_{44} & 0 \\
0 & 0 & 0 & 0 & 0 & p_{44}
\end{array}\right) \cdot\left(\begin{array}{c}
S_{1} \\
S_{2} \\
S_{3} \\
S_{4} \\
S_{5} \\
S_{6}
\end{array}\right) .
\end{aligned}
$$

The strain vector $\vec{S}$ is defined by derivatives of the displacement vector. In case of plasma induced birefringence, a local temperature distribution could cause local displacement through expansion. As such, the displacement vector components are directly coupled with the temperature gradient with an unknown coupling factor $\alpha$. Since the thickness of the BSO crystal used is much smaller than the radial dimensions, the derivatives to $z$ are neglected. This results in the following expression for $\vec{S}$ : 


$$
\vec{S}=\alpha\left(\begin{array}{c}
\partial^{2} T / \partial x^{2} \\
\partial^{2} T / \partial y^{2} \\
\partial^{2} T / \partial z^{2} \\
\partial^{2} T / \partial y \partial z \\
\partial^{2} T / \partial x \partial z \\
\partial^{2} T / \partial x \partial y
\end{array}\right)=\alpha\left(\begin{array}{c}
\partial^{2} T / \partial x^{2} \\
\partial^{2} T / \partial y^{2} \\
0 \\
0 \\
0 \\
\partial^{2} T / \partial x \partial y
\end{array}\right) .
$$

As a result, the retardance induced in the 0/90 system depends on a combination of the second derivative of the temperature distribution $T(x, y)$ to $x$ and $y$. The retardance induced in the diagonal system depends on $\partial^{2} T / \partial x \partial y$, see equation (15).

$$
\left\{\begin{aligned}
L B & =\frac{2 \pi \mathrm{d}}{\lambda} \Delta n_{0 / 90^{\circ}} \\
& =\frac{2 \pi \mathrm{d}}{\lambda} \frac{n_{o}^{3}}{2}\left(\left(p_{11}-p_{21}\right) S_{1}+\left(p_{12}-p_{11}\right) S_{2}\right) \\
L B^{\prime} & =\frac{2 \pi \mathrm{d}}{\lambda} \Delta n_{45 / 135^{\circ}} \\
& =\frac{2 \pi \mathrm{d}}{\lambda} n_{o}^{3} p_{44} S_{6}
\end{aligned}\right.
$$

\section{Obtaining the imaging Mueller matrices}

The complete imaging Mueller matrices are obtained using the polarimetry setup discussed above, right before and after the guided ionization waves impact the target. This is achieved by externally triggering the system using the current peak, shown in figure 1(b). As such, repetitive images can be taken at the exact same moment within the discharge cycle. The current peak is related to the ignition of the discharge within the capillary between the inner powered electrode and outer grounded ring [23, 24].

The plasma jet consists of a dielectric pyrex capillary with an outer diameter of $4 \mathrm{~mm}$. Inside the capillary is a stainless steel tube through which helium flows at $1 \mathrm{slm}$ and which is connected to a high voltage power supply, delivering a $30 \mathrm{kHz}$ sinewave with an amplitude of $2 \mathrm{kV}$. As a result, one guided ionization wave is formed within each period of $33 \mu$ s and impacts the target, which is $7 \mathrm{~mm}$ away from the end of the capillary. A grounded ring is attached around the dielectric capillary, $5 \mathrm{~mm}$ away from the end of the powered electrode and used to measure the current. A more comprehensive description of the plasma source is found in [23].

Being able to trigger the entire system externally is a crucial requirement, since 16 different states have to be examined and multiple exposures are desired to reduce noise. The guided ionization waves generated by the plasma jet allow for this, since these discharges are extremely reproducible. Every one of the 16 states of the intensity B matrix is obtained with multiple exposures of $1 \mu \mathrm{s}$. All of the exposures of a certain state are acquired at the same time delay relative to the current peak, but in a new plasma cycle.

A time delay is set relative to the current peak. When a delay is chosen of $1 \mu \mathrm{s}$, the ionization wave has not impacted the target and as such there are no induced electric fields, while with a delay of $8 \mu \mathrm{s}$, the impact has occurred already and the plasma is not present anymore. Yet there are surface charges that have been deposited by the ionization wave. This induces electric field in the target [24, 25].

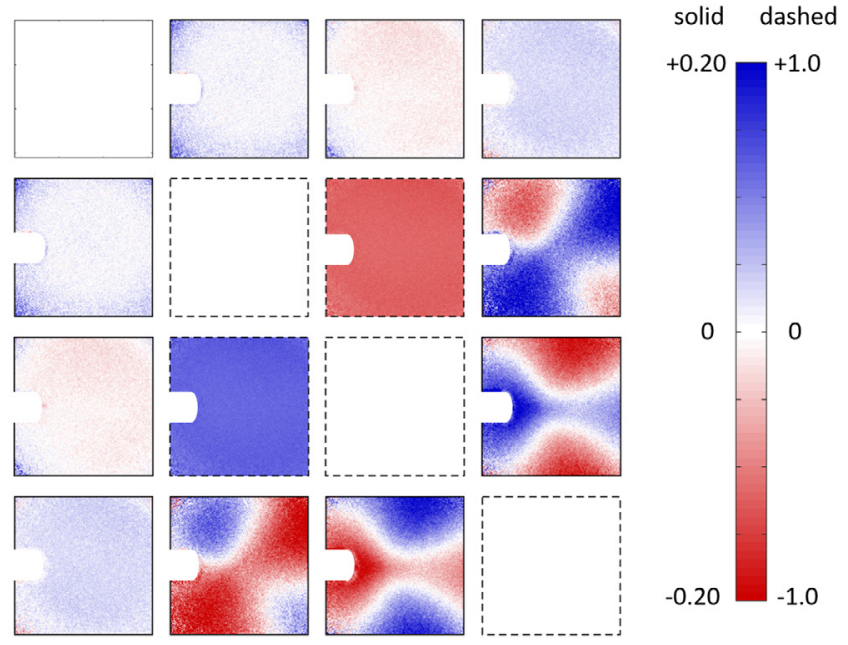

Figure 2. The resulting imaging $L_{m}$ matrix obtained after logarithmic decomposing the Mueller matrix obtained before impact of the guided ionization waves. Elements with a dashed border are shown from -1.0 to $1.0 \mathrm{rad}$ while the solid border indicates a colorscale of -0.2 to $0.2 \mathrm{rad}$. Spatial dimensions of the images are 15 by $15 \mathrm{~mm}$ and the area within the graphs that is partially blocked by the jet is removed.

For these measurements, any jitter present in the generation of the ionization waves or the impact at the target is negligible and not important, since changes are investigated before and after the impact and not during. It is shown in [24] that after impact, the charges at the surface remain constant for approximately $10 \mu$ s until the AC polarity changes and a weak back discharge removes all of the surface charge.

Since the plasma jet consists of many discharge events, a steady state temperature profile is expected through heat transport via the helium flow on the target. As such, the effect of temperature induced strain is observed both before and after impact of an ionization wave. Hence it is possible to separate the effect of electric field and the temperature induced strain.

The obtained Mueller matrices are decomposed using the logarithmic decomposition in order to retrieve the optical properties of the electro-optic target. The main focus lies on the change of linear retardance due to plasma interaction.

Figure 2 shows the logarithmic decomposed imaging Mueller matrix obtained right before impact of the guided ionization waves. The depolarization part is left out and as such only diattenuation and retardance are shown in the $L_{m}$ matrix. The BSO crystal is not inducing any depolarization, except for some scratches on the surface.

Diattenuation is zero both before and after impact, shown in matrix elements $\{1,2-4\}$ and $\{2-4,1\}$. Circular retardance is also constant throughout the plasma period, but non-zero because of the optical rotatory power of BSO [26], see matrix elements $\{2,3\}$ and $\{3,2\}$. Circular retardance is the only nonzero element in the Mueller matrix of BSO when there is no external influence.

Linear retardance both in the $0 / 90$ coordinate system $\{3,4\}$, as in the $45 / 135$ system $\{2,4\}$, shows a non-homogeneous pattern which changes after impact. This is visualized in figure 3 , showing the linear retardances before and after impact in the 


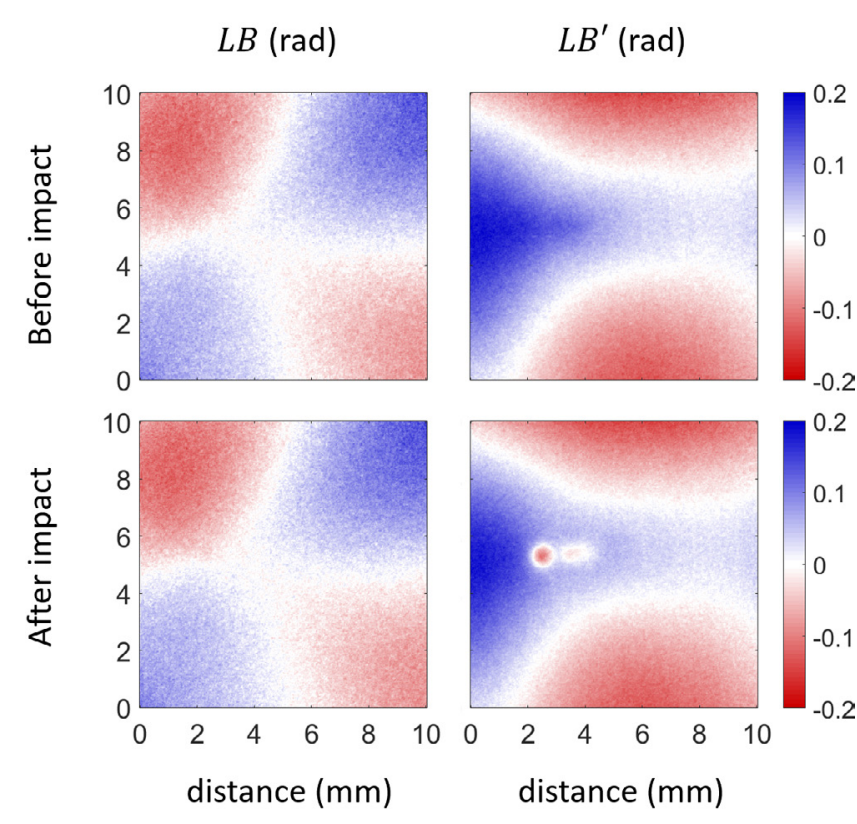

Figure 3. Linear retardances (rad) obtained before (delay $1 \mu \mathrm{s}$ ) and after (delay $8 \mu \mathrm{s}$ ) impact of guided ionization waves.

two coordinate systems. $L B$ does not seem to change significantly due to the impact, however $L B^{\prime}$ shows an additional pattern after the ionization waves have deposited charges at the surface of the target.

\section{Resulting electric field and temperature}

When the difference is taken between the linear retardances before and after the impact, the electric field can be calculated using the change of total linear retardance. This is shown in figure 4 . The pattern and values relate with previously obtained electric field patterns where a simpler Senarmont setup is used $[24,25]$. With this simpler setup, the focus lies solely on retardance in one optical coordinate system, while measuring the complete Mueller matrix allows a more comprehensive examination. This is further discussed below. The electric field pattern relates directly to the area where the ionization waves interact with the target and deposit charges.

The maximum electric field value observed is approximately $6 \mathrm{kV} \mathrm{cm}^{-1}$. This is an average value throughout the thickness of the crystal, which is $0.5 \mathrm{~mm}$. Only when the area where charges are deposited is much larger than the thickness of the sample, the average electric field will be equal to the surface value. Since that is usually not the case, a compensation procedure is needed to retrieve surface values of electric field and charge, as is proposed in [25]. Following this compensation procedure and based on the dimensions of the surface charge as it is observed in figure 4 , the average field of $6 \mathrm{kV} \mathrm{cm}^{-1}$ would relate to a surface field of approximately $10 \mathrm{kV} \mathrm{cm}^{-1}$.

The birefringence patterns that are observed in figure 3 both before and after the impact of the ionization waves, have been reported in previous work [24, 25]. However, as reported, the cause of these patterns was unknown. As shown in [25], the patterns become visible within the first few seconds when the plasma jet is turned on. By simple subtraction, the background patterns

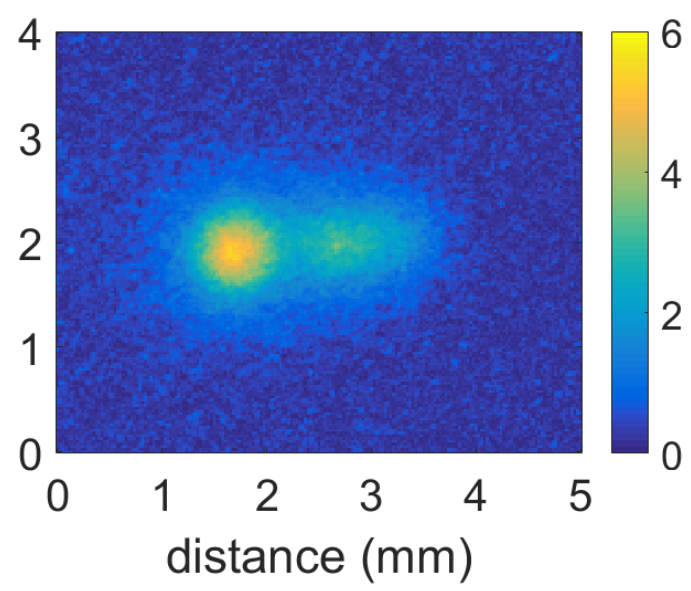

Figure 4. Resulting electric field pattern $\left(\mathrm{kV} \mathrm{cm}^{-1}\right)$ obtained using the difference in linear retardance before and after impact of ionization waves.

were easily removed to only focus on the electric field patterns. This new investigation indicates that the appearance of these background patterns is related to the temperature gradient present in the target caused by the plasma jet, as derived in equation (15).

Numerically, a temperature profile is calculated for which the second derivatives are comparable with the patterns observed in the background images. Due to the relative unknown parameters of the photo-elastic tensor of BSO, as well as the coupling constant $\alpha$, an optimization is performed to find the best conditions.

Figure 5 shows on the left the resulting numerically obtained temperature profile using parameters $p_{11}=0.16$, $p_{12}=0.13, p_{21}=0.12, p_{44}=0.12$ and $\alpha=15 \cdot 10^{-3} \mathrm{~m}^{2} \mathrm{~K}^{-1}$. The only additional boundary condition involved is choosing the room temperature in the bottom left corner. The jet is positioned horizontally on the left-hand side of the figure and as such the helium distributes the heat slightly towards the top right. The temperature profile is much broader than the area of impact of the ionization waves on the target.

A GaAs optical temperature probe is used to map pointwise the temperature measured on the backside of a glass plate with equal thickness of $0.5 \mathrm{~mm}$ under the influence of the plasma jet in equal conditions. The maximum temperature measured is approximately 14 degrees above room temperature. The measured temperature profile corresponds well with the numerically obtained one, see figure 5 . This supports our hypotheses that the background is due to a local increase in temperature. A proper calibration is needed before using the linear retardances obtained from Mueller polarimetry to investigate temperature profiles. This can be done for instance by inducing different temperature profiles by operating the plasma jet at different voltages or frequencies.

Concluding, we have used time resolved imaging Mueller polarimetry for the first time to investigate an electro optic target under exposure of guided ionization waves produced by the plasma jet. Analyses of the birefringence $L B$ and $L B^{\prime}$ revealed the spatial pattern and local values of the electric field induced in the target, as well as the temperature profile. It is the first simultaneous diagnostic for the separate imaging of these two important parameters. 


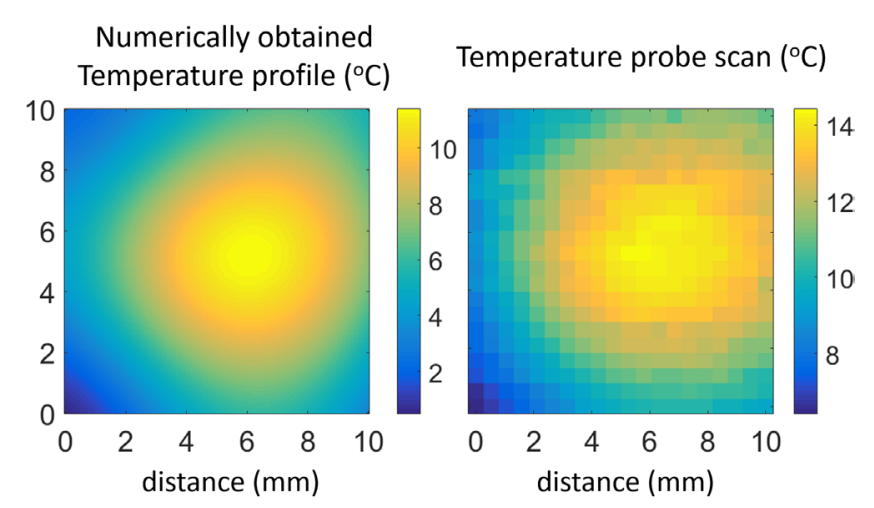

Figure 5. Temperature profiles obtained numerically by analysing the background retardance pattern (left) and by using a GaAs optical probe (right) scanned on the backside of a glass target, relative to room temperature.

Electric field or charge on an electro optic BSO crystal can be investigated also using a simpler setup, like a Senarmont setup as is used in e.g. [6, 7]. The advantage of using Mueller polarimetry is that the linear retardance is obtained in two different coordinate systems, instead of just one. Both depend on electric field and temperature in a different manner. So it is a more sensitive approach, since both can be used. This is important for instance when different crystals are examined showing a different response or when BSO is examined in a different way by using light not at normal incidence but at an inclined angle. With Mueller polarimetry only, the interpretation of the measured Mueller matrix or logarithmic decomposed matrix changes, not the measurement setup itself.

In addition to Mueller polarimetry, all of the optical information of the sample is obtained, not only retardance. For now, we have neglected any discussion about depolarization, because only small cracks on the surface of the BSO crystal cause depolarization. However, this technique can be used in future research to investigate many different samples that contain additional optical information like depolarization. This could include thin film biomedical tissue, plastics/polymers, catalytic surfaces, etc. Having a time resolved Mueller polarimetry setup would allow us to see optical changes due to the impact of a periodical and reproducible plasma source like the plasma jet. In general, the investigation of dynamical systems is now possible by using time resolved Mueller polarimetry, which to the best of our knowledge has not been done before.

\section{Acknowledgments}

This work was performed within the LABEX Plas@par project and received financial state aid managed by the Agence Nationale de la Recherche under the reference ANR-11IDEX-0004-02. Elmar Slikboer is also funded by the 'Chaire Energie Durable' at Ecole Polytechnique under the reference EXXI with the financial aid from EDF foundation.

\section{ORCID iDs}

Elmar Slikboer (i) https://orcid.org/0000-0002-7716-907X

Ana Sobota (1) https://orcid.org/0000-0003-1036-4513

Olivier Guaitella (1) https://orcid.org/0000-0002-6509-6934

Enric Garcia-Caurel @ https://orcid.org/0000-0001-8202-7810

\section{References}

[1] Foest R, Kindel E, Ohl A, Stieber M and Weltmann K D 2005 Plasma Phys. Control. Fusion 47 B525-36

[2] Kong M G, Kroesen G, Morfill G, Nosenko T, Shimizu T, van Dijk J and Zimmermann J L 2009 New J. Phys. 11115012

[3] Stoffels E, Flikweert a J, Stoffels W W and Kroesen G M W 2002 Plasma Sources Sci. Technol. 11 383-8

[4] Fridman G, Shereshevsky A, Jost M M, Brooks A D, Fridman A, Gutsol A, Vasilets V and Friedman G 2007 Plasma Chem. Plasma Process. 27 163-76

[5] Schlegel J, Köritzer J and Boxhammer V 2013 Clin. Plasma Med. $12-7$

[6] Sobota A, Guaitella O and Garcia-Caurel E 2013 J. Phys. D: Appl. Phys. 46327001

[7] Bogaczyk M, Wild R, Stollenwerk L and Wagner H E 2012 J. Phys. D: Appl. Phys. $451-11$

[8] De Martino A, Kim Y K, Garcia-Caurel E, Laude B and Drévillon B 2003 Opt. Lett. 28616

[9] Garcia-Caurel E, Ossikovski R, Foldyna M, Drévillon B and Martino A D 2013 Ellipsometry at the Nanoscale ed M Losurdo and K Hingerl (Berlin: Springer)

[10] Gil J and Ossikovski R 2016 Polarized Light and the Mueller Matrix Approach (Boca Raton, FL: CRC Press)

[11] De Martino A, Garcia-Caurel E, Laude B and Drévillon B 2004 Thin Solid Films 455-6 112-9

[12] Compain E, Poirier S and Drevillon B 1999 Appl. Opt. 38 3490-502

[13] Azzam R M A 1978 J. Opt. Soc. Am. 681756

[14] Ossikovski R 2011 Opt. Lett. 36 2330-2

[15] Arteaga O 2017 J. Opt. Soc. Am. A 34410

[16] Born M and Wolf E 1970 Principle of Optics (Oxford: Pergamon) pp 665-84

[17] Powell R C 2010 Symmetry, Group Theory, and the Physical Properties of Crystals (Lecture Notes in Physics vol 824) (New York: Springer) pp 330-40

[18] Malgrange C, Ricolleau C and Schlenker M 2011 Symmetry and Physical Properties of Crystals (Berlin: Springer) pp 407-15

[19] Duvillaret L, Railland S and Coutaz J L 2002 J. Opt. Soc. Am. B $192704-15$

[20] Pockels F 1894 Ueber den Einfluss des Elek-Trostatischen Feldes Auf Das Optische Verhal-Ten Piezoelektrischer Krystalle vol 39 (Göttingen: Dieterichsche)

[21] http://mt-berlin.com/frames_cryst/descriptions/photoref.htm

[22] Martienssen W and Warlimont H 2005 Springer Handbook of Condensed Matter and Materials Data ed W Martienssen and H Warlimont (Berlin: Springer) p 1121

[23] Sobota A, Guaitella O and Rousseau A 2014 Plasma Sources Sci. Technol. 23025016

[24] Slikboer E, Guaitella O and Sobota A 2016 Plasma Sources Sci. Technol. 25 03LT04

[25] Slikboer E, Garcia-Caurel E, Guaitella O and Sobota A 2017 Plasma Sources Sci. Technol. 26035002

[26] Vachss F and Hesselink L 1987 Opt. Commun. 62 159-65 